\title{
Population of tetranychidae mites on apple trees and methods of restraining the number of resistant races in crimea
}

\author{
E.B.Balykina ${ }^{2,}{ }^{*}$, T.S. Rybareva ${ }^{1}$, and L.P. Yagodinskaya ${ }^{2}$ \\ ${ }^{1}$ Federal State Budgetary Institution "All-Russian Plant Quarantine Center”, branch in the Republic of \\ Crimea, Simferopol \\ ${ }^{2}$ Federal State Budgetary Institution of Science "Nikitsky Botanical Garden — National Science \\ Center", Yalta, Republic of Crimea, Russia
}

\begin{abstract}
Analysis of apple tree phytosanitary state showed that the species composition of phytophage mites is labile and is subject to a constant shift of the share ratio. In 2012-2013, the apple orchards of Crimea were dominated by Amphytetranychus viennensis Zacher. Its share in the acarocomplex was $80 \%$. Since 2014 , the ratio has changed towards prevalence of Panonychus ulmi Koch. - 50\%. With this, share of A. viennensis decreased to $25.0 \%$. In some years there was mass reproduction of Tetranychus turkestani Ug et Nik and Tetranychus urticae Koch. The number of phytophage mites during the growing season depends on a number of factors: settlement to new areas, interspecies competition, reduction of feed base, occurrence of fungal diseases epidemics, increase in the number of natural enemies. The dependence of the phytophage mites population density on the numerical value of hydrothermal moisture index (HMI) was established: the higher the average daily air temperature in the absence of precipitation, the higher the population on the leaf apparatus. Appearance of resistant $\mathrm{P}$. ulmi races to five acaricides belonging to different chemical classes was established with the following active substances: spirodiclofen, fenpyroximate, pyridaben, fenazaquin , tebufenpyrad . A. viennensisshowed the appearance of acaricide-resistant races with active substances pyridaben and tebufenpyrad. In connection with the decrease in acaricide effectiveness against spider mites in the industrial apple tree plantations of Crimea, an anti-resistant protection strategy has been developed using predatory Phytoseiidae mites Phytoseiulus persimilis Ath. - H, Neoseiulus californicus McGregor, Amblyseius andersoni Chant.
\end{abstract}

\section{Introduction}

Phytophage mites cause significant harm to industrial fruit plantations, nurseries, vegetables of open and protected ground, as well as ornamental and flower crops. In Crimea, the share of the Acariformes order in the taxonomic structure of the apple tree

\footnotetext{
*Corresponding author: diza_alex_a@mail.ru
} 
entomoacarocomplex is from 14.2 to $17.5 \%$. Over the past decade, the apple tree has been dominated by two mite species of Tetranychidae family - Amphytetranychus viennensis Zacher и Panonychus ulmi Koch. In some years there was mass reproduction of Tetranychus turkestani Ug et Nik and Tetranychus urticae Koch.

The harmful arthropods species composition on apple trees constantly changes under the influence of biotic and abiotic factors. Pesticide treatments have a negative impact on the ecosystem of fruit plantations. Their repeated use leads to a change in the composition and structure of arthropods populations, to the replacement of some species with others, has a ruinous effect on biodiversity, and as a result, leads to mass reproduction of phytophage mites. [2-4].

Currently, studies of Russian $[1,5,7]$ and foreign scientists confirmed the appearance of acaricide-resistant races of spider mites. [8-11].

The resistance formation to the avermectin group preparations in common spider mite has been studied in the most detail. It is recorded in geographically dissociated T. urticae populations collected in the State of Florida, the Netherlands and the Canary Islands. It is noted that in the Dutch population, resistance occurs 2 years after treatment with abamectin, whereas in California the same species has been stable for 4 years since the treatment start. Abamectin resistance was recorded in Washington and Oregon in 1994-1995 in populations $T$. urticae in pear gardens after $7-8$ years of ubiquitous use of this acaricide. Four populations of highly resistant spider mites races were recorded when spraying hops with abamectin in Washington state. Since 1992 in Florida, abamectin has been widely used against common spider mite on strawberry plantations, and in 1999 there were numerous reports of ineffectiveness of this acaricide. [1,8-11].

In Germany, as a monitoring result of acaricide resistance of natural mites' populations larvae from France, Italy, Brazil and the United States, the appearance of three resistant populations after 7 generations was established. When assessing the resistance level of 11 T. urticae populations collected in 2001 in Colombia on roses, only one population sensitive to abamectin was revealed [8-11]. Laboratory tests in China confirmed appearance of resistant $T$. urticae race when treated with abamectin after 12 generations. $[1,11]$

T. urticaeraces identified in Belgium were resistant to acaricides with the following active substances: bifenthrin, dicofol and fenbutatin oxide, and no resistance to abamectin has been detected. [9] In Iraq, the natural population of common spider mite resistant to bromopropylate had no cross resistance to abamectin [10].

In Russia, the resistance problem is studied by S.Ya. Popov [5] and L.P. Yagodinskaya with Balykina E.B. and Rybareva T.S. [4, 7]. According to their data, Panonychus ulmi Koch developed resistance to 6 acaricides, Amphytetranychus viennensis Zacher - to three. [7] Specialists of VIZR have established the presence of cross resistance to preparations with aversectin $\mathrm{N}$ and abamectin active ingredients in $T$. urticae populations highly resistant to fenazaquin. Two types of mites were found in greenhouse farms of the Moscow region - T. urticae and Tetranychus dianthica Dosse, characterized by a high degree of phytoverm resistance [1].

Apple tree protection systems have been developed using three types of predatory Phytoseiidae mites - Phytoseiulus persimilis Ath. - H, Neoseiulus californicus McGregor and Amblyseius andersoni Chant. by the method of mass release and seasonal colonization. [4]

\section{Purpose of research}

To develop anti-resistant environmentally low-hazard methods of limiting the number and severity of spider mites in agrocenoses. 


\section{Materials and methods of research}

Object of research — spider mites Amphytetranychus viennensis Zacher and Panonychus ulmi Koch and three species of predatory Phytoseiidae mites - Phytoseiulus persimilis Ath. - H, Neoseiulus californicus McGregor and Amblyseius andersoni Chant.

Research was carried out in 2013-2020 in intensive apple plantations of Krasnogvardeysky district (JSC "Crimean Fruit Company") and two farms of Nizhnegorskiy district of Crimea (JSC" State Farm Vesna" and JSC "Pobeda").

Accounting of the number of spider and predatory mites was carried out by route survey method starting with the "sleeping bud" apple tree phenophase and ending with the harvest, with intervals of 7-10 days. Data on the quantitative composition of movable stages of phytophage mites and Phytoseiidae were obtained in the laboratory when observing leaf samples under a stereomicroscope.

The apple tree protection system for combating spider mites in fruit plantations and grape plantations was developed according to the methodology of Kuznetsov N.N. (2001), improved and adapted to consider the pesticides assortment change, as well as biological features of Phytoseiidae mites' species. [6].

In the laboratory, predatory mites were selected from leaf samples for micropreparations. Determination of predatory mites was carried out according to the determinants given in the book "Agricultural acarology". [6].

Phytoseiulus persimilis Ath., A. andersoni and A. californicus predator mites were used by two methods: "mass release", in which predators were released directly into the garden and "seasonal colonization", when the population was propagated in a soybean greenhouse on a common spider mites and further released into the garden with a release norm of 250300 individuals/every 10 th tree.

\section{Results and discussion}

As a result of a multi-year analysis of the phytosanitary apple tree state, it was established that the species composition of phytophage mites is labile and is subject to a constant shift of the share ratio, which is explained by the interspecies competition for forage base and habitat. As evidenced by the data presented in Figure 1, A. viennensis dominated in apple orchards of Crimea from 2012 to 2013, its share in the acarocomplex was $80 \%$. Since 2014 , the ratio has changed towards $R$. Ulmi prevalence (50\%). In the spring and summer period, the leaf apparatus was inhabited by these two species, at the end of the growing period there was the appearance of T. urticae and Tetranychus turkestani. Ug et Nik noted, in stone fruit gardens - Schizotetranychus pruni Oudemans.

Starting from 2017 to 2020 , the leading position in the industrial apple tree plantations was taken by $A$. viennensis and $R$ ulmi., the rest of the species were found in adjacent areas and in uncultivated gardens.

One of the limiting factors affecting the number of phytophage mites is fungal diseases damage. In the last 5 years, we have recorded the death of 1.0 to $3.0 \%$ of tetranychidae mites from fungal diseases. The species composition of pathogens is in the identification stage.

A great role on the dynamics of the number of this arthropods group was played by weather conditions of the growing season. It was found that in the spring period (April), the number of phytophage mites inhabiting leaves depends more on the percentage of overwintered individuals and return frosts at the time of exit from wintering places. So, in spring 2020, during return frosts $\left(-6^{\circ} \mathrm{C}\right.$ within three days) marked the death of A. viennensis females exiting diapause $(15.0-17.0 \%)$ and up to $20.0 \%$ of spawned $R$. ulmi. larvae. 


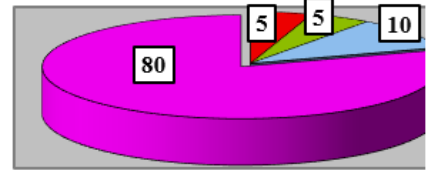

QPanonychus ulmi Koch

-Tetranychus urticae Koch

口Tetranychus turkestani Ug etNik

口Amphitetranychus viennensis Zacher $2012-2013$

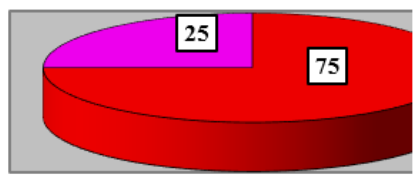

口Panonychus ulmi Koch $\mathbf{Q}$ Amphitetranychus vienner

$2017-2018$

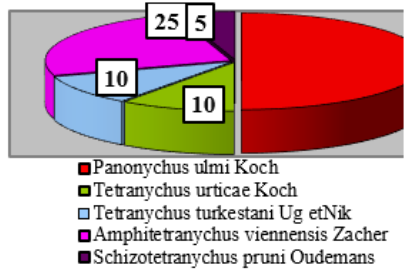

$2014-2016$

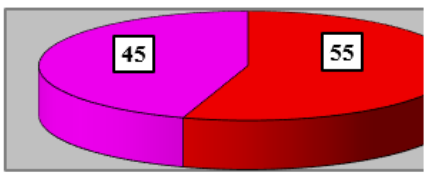

$\square$ Panonychus ulmi Koch $\square$ Amphitetranychus viennensi

$2019-2020$

Fig. 1. Species composition of apple orchards acarocomplex of Crimea, 2012 - 2020 (average).

In the period from May to September, the number of phytophage mites on leaves increases inversely proportional to the numerical HMI values, i.e. the higher the average daily temperature in the absence of precipitation, the higher the occupancy of the leaf apparatus (table 1).

Table 1. Population density of tetranychidae mites depending on HMI, $2015-2019$ (average).

\begin{tabular}{|l|c|c|c|c|c|c|c|c|c|}
\hline \multirow{2}{*}{ Indicator } & \multicolumn{8}{|c|}{ HMI } \\
\cline { 2 - 9 } & 0 & 0.2 & 0.4 & 0.6 & 0.8 & 1.0 & 1.2 & 1.4 \\
\hline P. ulmi & \multicolumn{8}{|c|}{ Movable stages, individuals/leaf } \\
\cline { 2 - 9 } max & 16.8 & 15.8 & 7.6 & 5.8 & 2.9 & 0.5 & 3.0 & 0.9 \\
& 32.7 & 22.5 & 19.8 & 32.0 & 15.6 & 6.0 & 5.8 & 1.2 \\
\hline A. viennensis & & & & & & & & \\
$\min$ & 11.8 & 9.6 & 8.5 & 4.7 & 1.9 & 0.7 & 1.2 & 0.7 \\
$\max$ & 37.2 & 19.7 & 19.3 & 20.0 & 10.5 & 4.2 & 2.9 & 3.0 \\
\hline
\end{tabular}

In 2020, the population density of two tetranychidae mites species began to increase in May at $\mathrm{HMI}=0.8$. In the future, with a decrease in the numerical value of HMI to $0.2-0.3$, the population increased to 15 - 25 individuals/leaf (Figure 2).

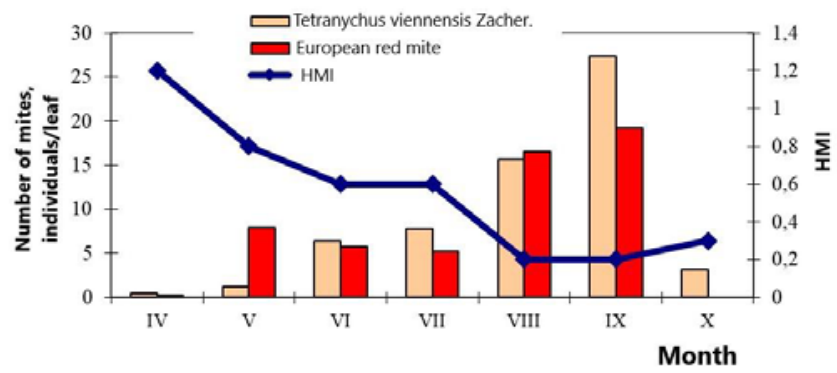

Fig. 2. Amphytetranychus viennensis Zacher and Panonychus ulmi Koch numbers depending on the hydrothermal coefficient. Republic of Crimea, 2020

Multiple uncontrolled use of pesticides leads to a decrease in their biological efficacy and, as a result, a rapid recovery of the tetranychidae mites' population after treatment. The appearance of European red mite races resistant to five acaricides belonging to different 
chemical classes was established with the following active substances: spirodiclofen, fenpyroximate, pyridaben, fenazaquin, tebufenpyrad . In A. viennensis mites, the appearance of resistant races to acaricides with active substances pyridaben and tebufenpyrad was noted. Until 2019, insectoacaricides from the avermectin (a.s. abamectin) chemical class and a combined preparation with active substances abamectin + spiromesifen showed $90-99 \%$ of biological effectiveness in relation to A. viennensis and P. Ulmi. [10]. In 2020, a decrease in the acaricides effectiveness of abamectin classes was established at $11-20 \%$, and the abovementioned combined preparation - at $10-13 \%$ with 3-5 times use per season (table 2).

Table 2. Biological efficacy (\%) of acaricides against Panonychus ulmi Koch and Amphytetranychus viennensis Zacher

\begin{tabular}{|c|c|c|c|c|c|c|c|c|}
\hline \multirow{2}{*}{$\begin{array}{c}\text { Active } \\
\text { substance }\end{array}$} & \multicolumn{4}{|c|}{ A. viennensis } & \multicolumn{5}{c|}{ P. ulmi } \\
\cline { 2 - 10 } & \multicolumn{4}{|c|}{ years } & \multicolumn{5}{c|}{ years } \\
\cline { 2 - 10 } & $2013-2015$ & 2016 & $2017-2019$ & 2020 & $2013-2015$ & 2016 & $2017-2019$ & 2020 \\
\hline Spirodiclofen & 70.8 & - & - & - & 70.8 & - & - & - \\
\hline Fenpyroximate & 68.0 & - & - & - & 55.0 & - & - & - \\
\hline Pyridaben & 78.7 & - & - & - & 71.7 & 72.3 & - & - \\
\hline Fenazaquin & 89.7 & - & - & - & 86.7 & 88.2 & 85.5 & - \\
\hline Clofentezine & 75.7 & 90.0 & 88.0 & - & 75.7 & 90.0 & 85.0 & 76.8 \\
\hline Tebufenpyrad & - & - & - & - & 48.5 & - & - & - \\
\hline Abamectin & - & 99.0 & 94.3 & 89.0 & - & 96.8 & 93.7 & 80.0 \\
\hline $\begin{array}{c}\text { Abamectin + } \\
\text { titronic acids }\end{array}$ & - & 99.8 & 97.8 & 90.5 & - & 99.0 & 99.0 & 87.4 \\
\hline
\end{tabular}

In response to the acaricides efficiency decrease against spider mites in the industrial apple tree plantings of Crimea, an anti-resistant protection strategy has been developed using predatory Phytoseiidae mites - Phytoseiulus persimilis Ath. - H, Neoseiulus californicus McGregor, Amblyseius andersoni Chant.

It was established that it is advisable to release $P$. persimilis at the rate of 200-300 individuals/tree with a pest number of 3-4 individuals /leaf in phytophage mites mass accumulation locations in the spring period at air temperature of $16.2^{\circ} \mathrm{C}$ and $72 \%$ humidity. The optimal predator-victim ratio is 1:15 - 1:20. At the same time, after 14 days after release, the number of phytophage mites decreases to 1.0-1.5 individuals/leaf. With a pest number of $7.0-8.0$ individuals/leaf, it is effective to introduce predators by the "mass release" method at the rate of 500 individuals/every 3rd tree or for each tree within the heart.

$P$. rersimilis release can be combined $A$. andersoni. As a result, acarofauna of predatory mites is formed, the first species effectively (by $50-60 \%$ ) reduces the number of phytophage mites, the second species increases its number, which allows to reduce the pest number by the end of the second decade of June to 2-3 individuals/leaf.

In the summer period, only $A$. andersoni or $N$. salifornicus are released since $P$. rersimilis does not tolerate high temperatures and low humidity. The two-fold release of these species at a phytophage number close to the threshold (6,0 individuals/leaf) allows to restrain the number of phytophage mites at an economically imperceptible level throughout growing season. 


\section{Conclusions}

It was established that the phytophage mites species composition in apple orchards of Crimea is labile and subject to a constant shift of the share ratio. Changes in the acarocomplex structure occur as a result of interspecies competition for forage base and habitat. Weather conditions are a significant factor influencing the seasonal dynamics of numbers. The established correlation dependency between hydrothermal indicators and phytophage mites population density indicates an increase in the breeding potential under adverse conditions.

The damage of tetranychidae mites by fungal diseases is not a significant limiting factor, because their recorded death is within $1.0-3.0 \%$ of the population.

Multiple uncontrolled pesticides application in gardens leads to a decrease in their biological efficacy, rapid recovery of tick population, and the emergence of resistant races. The appearance of $P$. ulmi. races resistant to five acaricides belonging to different chemical classes was established with the following active substances: spirodiclofen, fenpyroximate , pyridaben, fenazaquin, tebufenpyrad; A. viennensis showed the appearance of acaricideresistant races with active substances pyridaben and tebufenpyrad.

To prevent the appearance of high-resistant $P$. ulmi. and A. viennensis races, methods of introducing predatory mites by "mass release" and "seasonal colonization" have been developed. As a result, predatory mites acarofauna is formed in the gardens, which in the first year of their release allows to reduce the number of phytophage mites by $50-60 \%$ and restrain the pests number at an economically imperceptible level.

\section{References}

1. M.A. Alekseev, Agrochemistry, 2, 82 (2011)

2. E.B. Balykina, Most important phytophages of garden agrocenoses of Crimea, 352 (2020)

3. E.B. Balykina, L.P. Yagodinskaya, T.S. Rybareva, N.V. Balitskiy, Bulletin of the State Nikitskiy Botanical Garden, 123, 58 (2017)

4. E.B. Balykina L.P. Yagodinskaya T.S. Rybareva D. A. Korzh, O.V. Ivanova, Farming, 7, 30 (2020)

5. S.A. Burbentsov, S.Ya. Popov, Achievements of science and technology of AIC, 1, 21 (2007)

6. I.Z. Livshits, V.I. Mitrofanov, A.Z. Petrushov, Agricultural acarology, 348 (2013)

7. L.P. Yagodinskaya, Collection of scientific works of the State Nikitsky Botanical Garden, 142, 128 (2016)

8. N. Rauch, R. Nauen, Pest. Biochem. Physiol., 74(2), 91 (2003)

9. W.-D. Zhao, K.-Y. Wang, X.-Y. Jiang, M.-Q Yi, Acta Entomol. Sinica, 46(6), 788 (2003)

10. I.J. Al-Jboory, A.I. Al-Sammarie, R.E. Jumida, Resist. Pest. Manag. Newslett., 15(2), $58(2006)$

11. J.G. Morse, F.J. Byrne, E.C Humeres et al., Proceed. of the California avocado research symp., 43 (2004) 